\section{Lens development}

\begin{abstract}
This review gives a brief account of the main processes of lens development, including induction, morphogenesis, differentiation and growth. It describes what is known about the molecules and mechanisms that control and regulate these processes. Some of the recent progress made in understanding the molecular basis of lens development is highlighted along with some of the challenging areas for future research.
\end{abstract}

Key words Fibroblast growth factor, Induction, Lens development, Morphogenesis, Transcription factors, Transforming growth factor-beta

The eye lens has been a popular system for studying the processes and mechanisms of development. For example, at the beginning of this century there was much interest in embryonic induction and studies on the lens were crucial for gaining fundamental insights into the nature and importance of this phenomenon. In recent years the application of new molecular technologies has revolutionised lens developmental research. However, our understanding of the main processes of lens development, including induction, morphogenesis, differentiation and growth, remains fragmentary. The aim of this short review is to briefly describe these processes and to identify some of the recent advances that have been made in understanding the molecular basis of their control.

\section{Induction}

The lens arises from head ectoderm that is associated with an outpocketing of the developing forebrain: the optic vesicle (Fig. 1A). Shortly after these two tissues become closely associated, lens morphogenesis begins and the ectoderm thickens to form the lens placode (Fig. 1B, C). Because of their close spatial association embryologists hypothesised that the optic vesicle was the lens inducer. Whilst early experiments with amphibians showed that removal of the optic vesicle primordium resulted in no lens formation, ${ }^{1}$ later experiments produced contradictory results; in some cases a lens-like structure formed from the ectoderm even when the optic vesicle was removed at the early neurula stage (reviewed in McAvoy ${ }^{2}$ ). One interpretation of these results was that other tissues besides the optic vesicle were involved in lens induction.

It was some time before this hypothesis was investigated. Jacobson and colleagues ${ }^{3}$ provided evidence from explantation experiments with amphibians that the endodermal wall of the future pharynx and presumptive heart mesoderm had some lens-inducing capacities. More recently, from a comprehensive series of transplantation experiments with amphibians, Grainger and colleagues ${ }^{4}$ emphasised a key role for the anterior neural plate as an early inducer of lens ectoderm. Overall their results indicate that a broad region of head ectoderm acquires a 'lens-forming bias' well before its interaction with the optic vesicle, the latter being important for localising and promoting this lens-forming ability in the appropriate region. ${ }^{4,5}$

Although it is generally recognised that lens development depends on a sequence of inductive interactions, little is known about the inducing molecules that are involved. More is known about the consequences of these inductive interactions and currently there is much interest in the key regulatory genes that are activated in the presumptive lens ectoderm. Among these the highly conserved transcription factor, Pax-6, has been the focus of much attention. In Drosophila targeted expression of Pax-6 to imaginal discs results in the formation of ectopic eyes and it has been referred to as the 'master gene for eye development'. ${ }^{6}$ More recently in Xenopus, Altmann et al. ${ }^{7}$ showed that ectopic expression of Pax-6 resulted in formation of ectopic lenses in whole embryos as well as in animal cap explants, indicating that in vertebrates, as well as in Drosophila, Pax-6 can direct the differentiation of major components of the eye. They concluded that 'the establishment of Pax- 6 expression in the presumptive lens ectoderm during development is therefore likely to be an important response of lens-competent ectoderm to early lens inducers' ${ }^{7}$ Consistent with this, it has been shown in the mouse embryo that the early Pax-6 mRNA expression is in a broad domain of surface ectoderm. Later Pax-6 appears to be downregulated, disappearing from regions of the ectoderm but still being expressed in the presumptive lens regions
J.W. McAvoy

C.G. Chamberlain

R.U. de longh

A.M. Hales

F.J. Lovicu

Department of Anatomy and Histology and Institute for Biomedical Research University of Sydney Sydney, Australia

J.W. McAvoy Department of Anatomy and Histology (F13) The University of Sydney NSW 2006, Australia Fax: +61293512813 e-mail: johnmca@anatomy.usyd.edu.au 


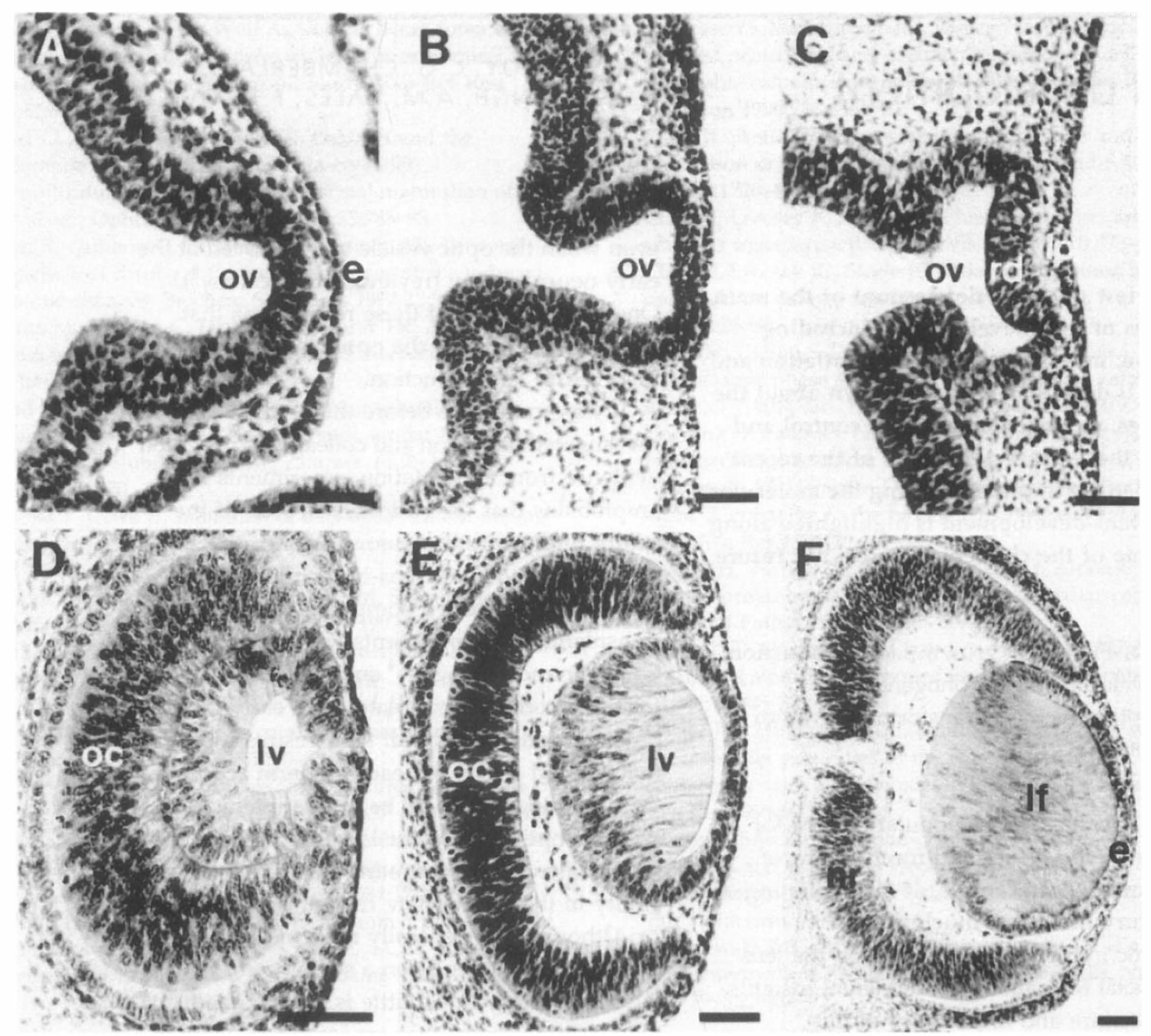

Fig. 1. Mid-sagittal paraffin sections through the optic primordia from E10-14 rat embryos stained with haematoxylin and phloxine showing early lens morphogenesis. At E10 (A) the lateral neuroepithelium of the diencephalon has evaginated to form the optic vesicle (ov) and this has come into close proximity with the head ectoderm (e) that is destined to form lens. In early E11 embryos (B) the optic vesicle (ov) is closely associated with the ectoderm. In late E11 embryos (C) both the ectoderm and the neuroepithelium are thickened along the region of close proximity, forming the lens placode (lp) and retinal disc ( $r d)$, respectively. Invagination of the lens placode and optic vesicle on day $12(D)$ leads to the formation of the lens pit/ vesicle (lv) and optic cup (oc), respectively. During E13 (E) the lens vesicle detaches from the optic cup (oc) and the posterior lens vesicle cells (lv) elongate to form primary lens fibre cells leading to narrowing of the vesicle lumen. Vitreous and hyaloid vasculature is beginning to form between the developing lens and retina. By E14 (F) the lens vesicle lumen has disappeared and the primary lens fibres (lf) have contacted the anterior lens vesicle cells which form the epithelium (e). The inner layer of the optic cup has begun to differentiate into the neural retina (nr). Adapted from de Iongh and McAvoy. ${ }^{76}$ Scale bars represent: $(A), 50 \mu \mathrm{m} ;(B, C), 75 \mu \mathrm{m} ;(D, E, F), 100 \mu \mathrm{m}$.

adjacent to the optic vesicles. ${ }^{8}$ Pax-6 is expressed in the lens during morphogenesis and continues to be expressed in the lens epithelium during embryonic and postnatal development, indicating that it is a key regulator throughout this continuous process (Fig. 2).

A number of other transcription factor gene families are expressed in the lens during eye development. These include GH6, ${ }^{9} \mathrm{Eya}_{,}{ }^{10} \mathrm{Maf} / \mathrm{Nrl}{ }^{11-13} \mathrm{Msx},{ }^{14,15}$ Prox $^{16,17}$ Pitx/Rieg, ${ }^{18}$ Six ${ }^{19,20}$ and Sox. ${ }^{21,22}$ Several of these genes have been shown to be essential for eye induction and development. For example, sine oculis (so) and eyes absent (eya), which are the founding members of the mammalian Six and Eya gene families, are required for eye development. Eya, like Pax-6, has been shown to induce ectopic eyes in Drosophila ${ }^{10}$ and Six-3, ectopic lenses in fish. ${ }^{20}$ It has been proposed that these transcription factors form a complex and act with Pax- 6 to regulate eye development in vertebrates and invertebrates. ${ }^{23}$ Overlapping expression patterns of these

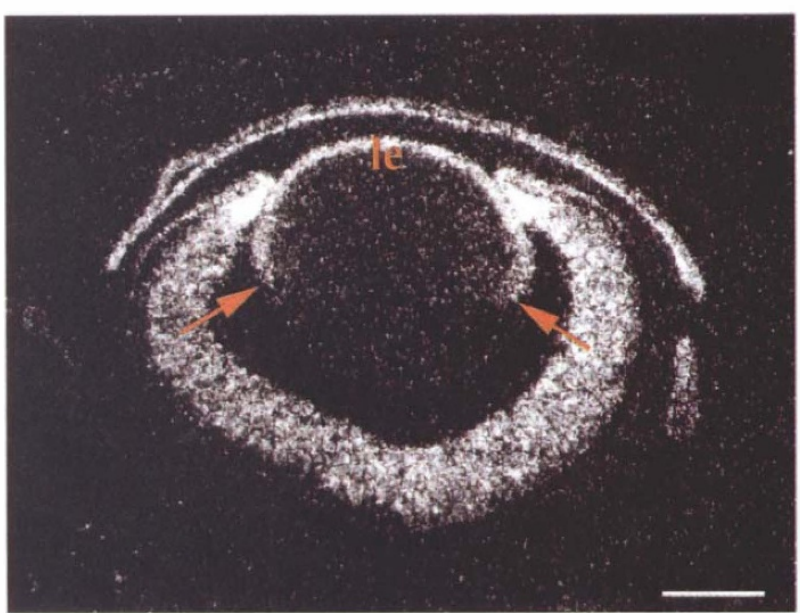

Fig. 2. Expression of Pax-6 mRNA in the developing mouse eye at E15. Dark-field microscopy shows hybridisation with the antisense probe for Pax-6. The signal is strong in the lens epithelium (le) but disappears during the early stages of fibre differentiation (arrows). Scale bar represents $250 \mu \mathrm{m}$. 


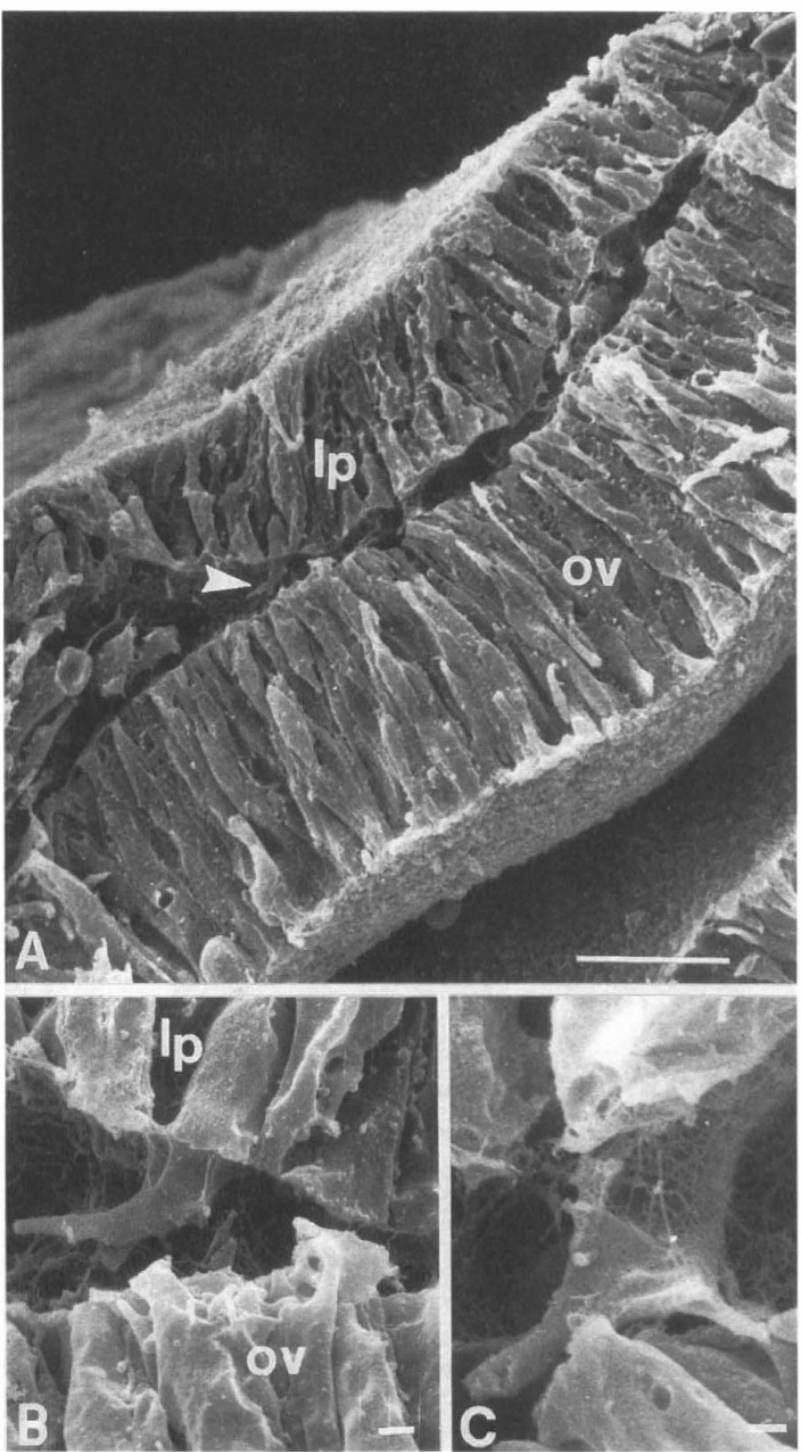

Fig. 3. Late in the E11 rat embryo, the lens placode (lp) and optic (ov) begin invagination. (A) Cytoplasmic processes extend across the space between the tissues (arrowhead). (B), (C) Cytoplasmic processes extend from the lens placode (lp) and optic vesicle (ov). Fibrils are often associated with the processes. In (C), thin processes branch from a thicker process and appear to make contact with the optic vesicle. Adapted from McAvoy. ${ }^{77}$ Scale bars represents $25 \mu \mathrm{m}$.

genes in the eye primordia (optic vesicle and lens placode) suggest they may also subsequently be involved in regulating expression of other downstream lens transcription factors such as L-Maf, Prox-1, Pitx-3 and Sox-1. Some of these in turn may interact with lensspecific genes; for example, L-Maf ${ }^{12}$ and Sox $-1^{22}$ have been shown to bind and activate promoter elements on crystallin genes.

\section{Morphogenesis}

As described above, the early stages of lens morphogenesis are characterised by a close physical association between the presumptive lens and optic vesicle (Fig. 1). Outgrowth of the optic vesicle results in its coming to lie directly under the presumptive lens ectoderm (Fig. 1A, B). Although they are closely

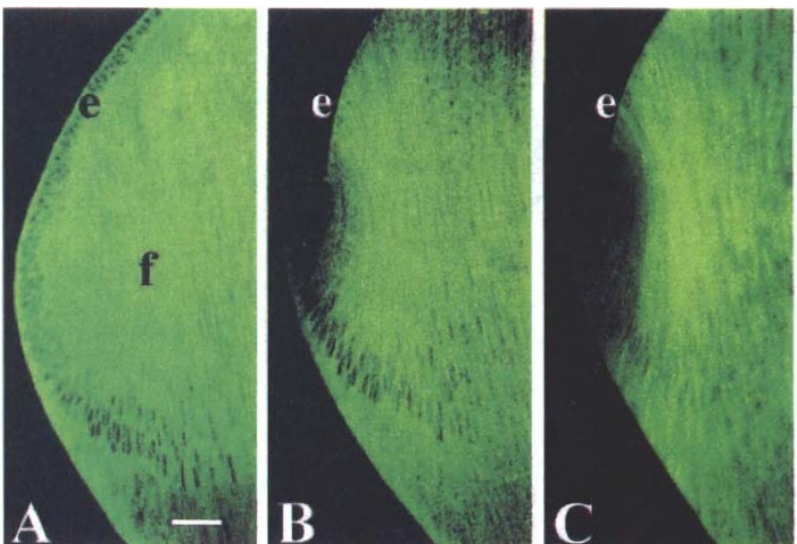

Fig. 4. Typical distribution of crystallins in the neonatal rat lens. Immunohistochemistry carried out on serial sections shows $\alpha$-crystallin ( $A)$ is detected in both lens epithelial cells (e) and fibre cells (f). $\beta$-Crystallin (B) is first detected early in fibre elongation just below the lens equator (see Fig. 9) and $\gamma$-crystallin (C) is first detected in young fibre cells in the lens cortex. Neither $\beta$-nor $\gamma$-crystallins are detected in the lens epithelium. Adapted from McAvoy. ${ }^{27}$ Scale bar represents $50 \mu \mathrm{m}$.

associated, the optic vesicle and presumptive lens ectoderm do not make complete contact; a narrow gap, across which the basal surfaces of the cells face each other, is maintained (Fig. 3). Mesodermal cells which generally underlie other regions of ectoderm are largely excluded from this gap. Once in close proximity to each other, the presumptive lens ectoderm and optic vesicle send out thick cytoplasmic processes from their basal surfaces. Mostly these processes extend only partly across the gap, although occasionally a process does appear to bridge the gap. ${ }^{24} \mathrm{~A}$ fibrillar network builds up between the two tissues and appears to be the basis for the strong adhesion between them. During this time the presumptive lens thickens to form the placode and then invaginates together with the optic vesicle to form lens pit and optic cup, respectively (Fig. 1C, D). Adhesion between these two tissues is probably important for coordinating their morphogenetic movements. As the lens pit deepens it finally breaks away from the ectoderm to form the lens vesicle. Cell death at the borders of the lens rudiment may facilitate the separation of the lens pit/vesicle from the ectoderm. ${ }^{25}$

\section{Differentiation and growth}

The next major event in lens development involves the differentiation of two forms of lens cells from the lens vesicle: cells in the posterior half of the vesicle elongate and differentiate to form the primary fibres, whereas cells in the anterior vesicle differentiate into the epithelium (Fig. 1E, F). In this way the lens acquires its distinctive polarity. The lens grows rapidly during late embryonic and early postnatal stages by cell division and differentiation. Cell divisions predominantly occur in the epithelial region just above the lens equator known as the germinative zone. ${ }^{26,27}$ The progeny of cell divisions migrate, or are displaced, below the equator into the 


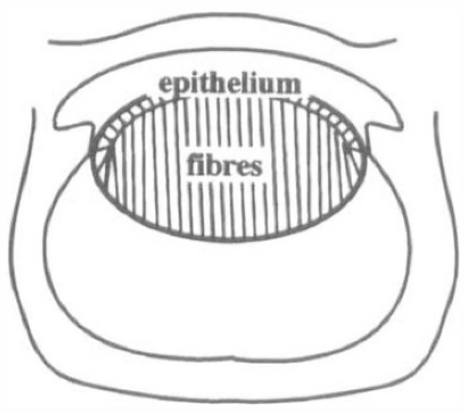

\section{LENS INVERSION}
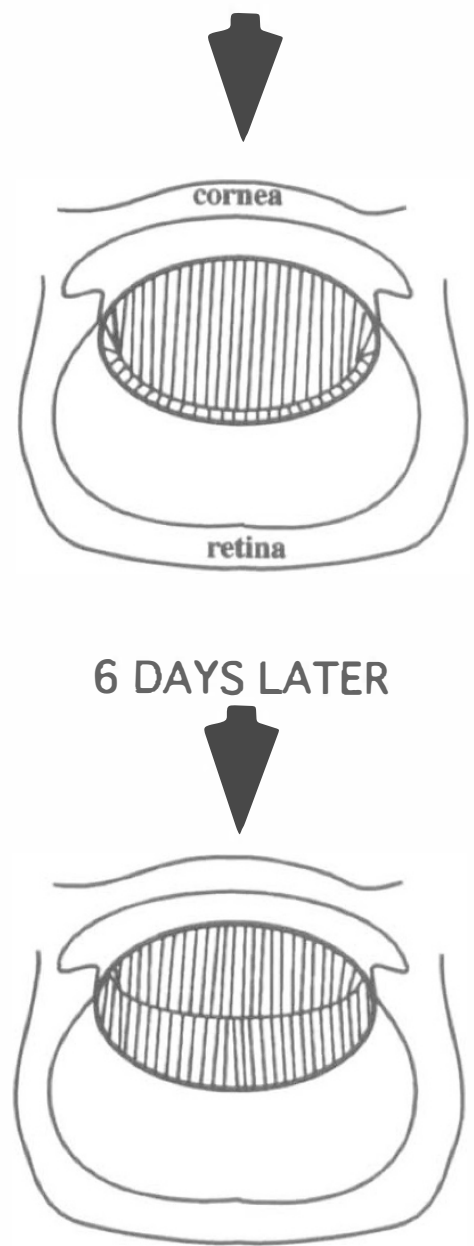

Fig. 5. Diagrammatic representation of the lens inversion experiment carried out by Coulombre and Coulombre. ${ }^{30}$ The lens of a 5-day embryonic chicken was turned through $180^{\circ}$ so that the lens epithelium faced the posterior segment rather than the anterior segment. Six days later, in this new environment, the epithelial cells had elongated to form fibre cells. transitional zone, where they elongate and differentiate into fibre cells (see Fig. 9 for definition of these zones). In this way, new fibre cells are continuously added to the fibre mass throughout life. Thus, the lens continually grows and maintains its distinct polarity with the monolayer of epithelial cells restricted to the anterior compartment.

Lens differentiation also involves the acquisition of specialised patterns of protein synthesis. Crystallins are the most abundant proteins in the lens and these progressively accumulate during embryogenesis and growth. In mammals, $\alpha$-crystallin appears first during lens morphogenesis and is characteristically present in all lens cells, ${ }^{27-29}$ whereas $\beta$ - and $\gamma$-crystallins appear later in morphogenesis and are restricted to fibre cells (Fig. 4).

A better understanding of how the ocular environment influences the process of lens fibre differentiation and lens polarity came from the classical lens inversion experiments of Coulombre and Coulombre. ${ }^{30}$ They turned the chicken lens through $180^{\circ}$ so that the epithelial cells, which normally faced the aqueous and cornea, faced the vitreous and neural retina instead (Fig. 5). In this new environment, the epithelial cells elongated and differentiated into fibre cells. Similar lens inversion experiments using mouse eyes confirmed that this phenomenon also occurred in mammals. ${ }^{31}$

These experiments indicated that the lens was receiving a fibre-differentiating signal from the optic cup environment.

\section{FGF induces fibre differentiation in vitro}

To identify the fibre-inducing influence in the mammalian eye we used a rat lens epithelial explant system. This was central to the identification of members of the fibroblast growth factor (FGF) family as potent inducers of fibre differentiation. FGF induces morphological changes characteristic of fibre differentiation accompanied by the accumulation of fibre-specific $\beta$ - and $\gamma$-crystallins ${ }^{32,33}$ (Fig. 6). Cell proliferation and migration are also observed as early responses to FGF. ${ }^{34}$ The explants become multilayered as attenuated cells migrate over others that retain a normal epithelial attachment to the capsule. ${ }^{35}$ Cells in FGFtreated explants also undergo a sequence of structural
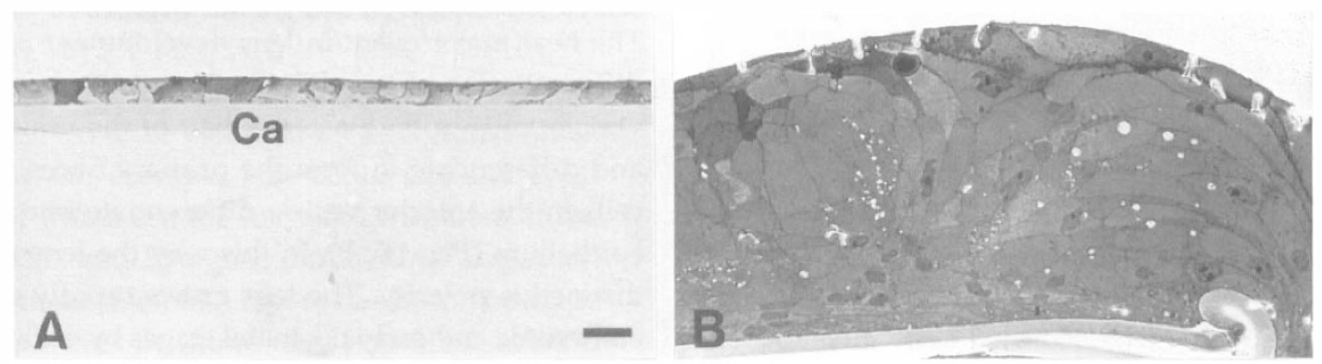

Fig. 6. Responses observed in epithelial explants cultured with FGF. Sections of explants cultured without FGF (A) or with FGF (B) for 10 days and stained with azur II-methylene blue. Without FGF the cells in the explant maintained a characteristic cuboidal epithelial morphology and remained as a monolayer on the lens capsule (Ca), whereas in the presence of FGF the explant became significantly thicker due to enlargement and multilayering of the cells. Many were elongated and showed features of fibre cells. Adapted from McAvoy et al. ${ }^{50}$ Scale bar represents $20 \mu \mathrm{m}$. 

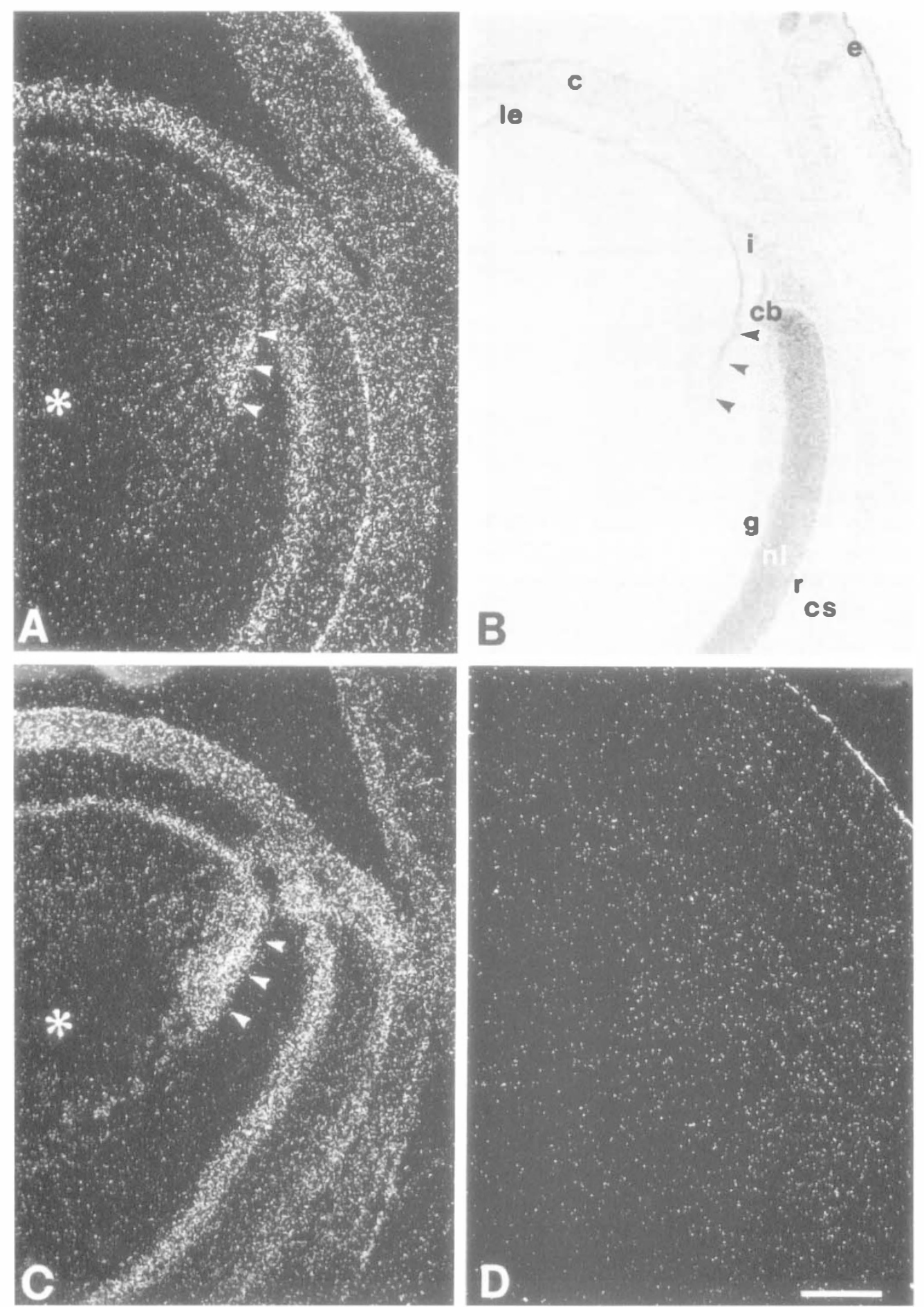

Fig. 7. Expression of FGF-1 and FGF-2 mRNA in the embryonic rat lens at E20. Dark-field micrographs show hybridisation with the antisense probe for FGF-1 (A) and FGF-2 (C) and the sense probe for FGF-1 (D). (B) Bright-field micrograph of an adjacent section. Both FGF-1 and FGF-2 are expressed in anterior lens epithelium (le) and equatorial region of the lens, with the strongest signal found in early lens fibres of the transitional zone (arrowheads). Signal was almost absent in the more mature fibres near the centre of the lens (asterisk). For both FGFs signal was detected in eyelids (e), cornea (c), ciliary body (cb), iris (i), various layers of the retina, particularly the ganglion cells ( $g$ ) and choroid/sclera (cs). Only background signal was detected with the sense probe for FGF-1 (D). (nl), neuroblast layer; $(r)$, pigmented epithelium. From Lovicu et al, ${ }^{46}$ with permission. Scale bar represents $200 \mu \mathrm{m}$.

changes: cell elongation, reduction in cytoplasmic organelles, formation of specialised cell-cell junctions and nuclear pyknosis with distinctive nucleolar changes. ${ }^{35-37}$ These changes are all features of lens fibre differentiation in the lens in situ. ${ }^{38-40}$

In situ, $\beta$-crystallin appears before $\gamma$-crystallin as lens cells undergo fibre differentiation ${ }^{27,28}$ (Fig. 4). A similar progression of events was observed in studies of neonatal rats cultured with FGF. ${ }^{41,42}$ Subsequently it was shown that, in explants cultured with FGF, mRNAs for the various crystallins show a similar sequential increase. ${ }^{43}$ The pattern of accumulation of $\alpha-, \beta$ - and $\gamma$-crystallins observed consistently in these studies reproduces the pattern of expression of these proteins that is part of the lens fibre differentiation process in situ. ${ }^{27}$ 


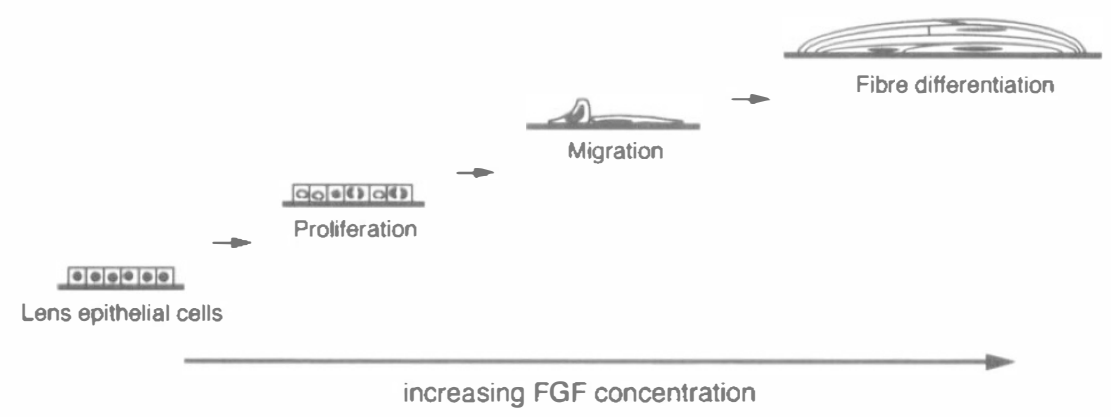

Fig. 8. Diagram illustrating the three different responses to FGF observed in lens epithelial explants in vitro and their sequential stimulation by increasing concentrations. From Chamberlain and McAvoy, ${ }^{45}$ with permission.

\section{A role for FGF in vivo}

The results of explant studies in our laboratory showed that FGF-induced fibre differentiation faithfully reproduces many of the molecular and structural events associated with this process in vivo. However, for FGF to be involved in fibre differentiation in situ it must be available to lens cells.

\section{Distribution of FGF}

Currently there are 18 members of the FGF family: FGF-1 to FGF-18. ${ }^{44}$ FGF-1 and FGF-2 were the first FGFs to be identified and their distribution in the eye has been studied extensively; for most of the more recent additions to the family, detailed distribution studies have not yet been carried out. Using immunohistochemical and biochemical methods we showed that, in addition to being present in lens cells and lens capsule, FGF-1 and FGF-2 are present in the ocular media that bathe the lens and tissues near the lens including the retina, cornea, ciliary body and iris (reviewed in Chamberlain and McAvoy ${ }^{45}$ ). In situ hybridisation studies showed that FGF-1 and FGF-2 mRNAs have a ubiquituous distribution in eye tissues similar to that of their respective proteins ${ }^{46}$ (Fig. 7). FGF-12 is the only other FGF so far reported to be expressed in the lens. ${ }^{47}$ FGF- $3,{ }^{48}$ FGF- $5^{49}$ and FGF- $12^{47}$ are also expressed in retina. Thus a number of FGFs are potentially available to lens cells. As a result of the wide distribution of FGF in both anterior and posterior segments of the eye the question arises as to how fibre differentiation is spatially restricted to the posterior segment. Normally the only cells that undergo fibre differentiation are those below the lens equator; this is crucial for maintaining lens polarity during the lifelong process of lens growth. Indications as to how FGF may be involved in influencing these growth patterns arose from dose-response analyses of lens epithelial explants.

\section{Proliferation, migration and fibre differentiation: FGF dose-dependence}

Detailed analysis of explants cultured with FGF identified three distinct cellular responses: proliferation, migration and fibre differentiation (reviewed in Chamberlain and McAvoy ${ }^{45}$ ). Experiments carried out to determine the dose-response characteristics showed that half-maximal stimulation of proliferation, migration and fibre differentiation occurred at $0.15,3$ and $40 \mathrm{ng} / \mathrm{ml}$ of FGF-2, respectively ${ }^{34}$ (Fig. 8). Therefore, the concentration of FGF in the culture medium influences the nature of the response of lens epithelial cells both qualitatively and quantitatively, with proliferation, migration and fibre differentiation being induced sequentially as the concentration is increased. At fibredifferentiating concentrations, this response soon overrides the proliferation and migration responses.

\section{Development of the FGF gradient hypothesis}

Cellular behaviour in the lens is spatially ordered. Proliferation, migration (or displacement) and fibre differentiation occur in an anteroposterior sequence in distinct compartments of the lens. On the basis of our findings that FGF induces proliferation, migration and fibre differentiation in a progressive dose-dependent manner, we put forward the hypothesis that normal lens cell behaviour is determined by an anteroposterior gradient of FGF stimulation ${ }^{34,50}$ (Fig. 9). It needs to be emphasised that, while the sequence of cellular responses indicated in Fig. 8 could be achieved in vitro simply by using increasing concentrations of FGF, the situation in vivo is likely to be more complex. Consequently, the term 'FGF stimulation' is used in the gradient hypothesis, rather than 'FGF concentration'. FGF stimulation takes into account the fact that many different modulatory influences are likely to be involved (reviewed in Chamberlain and McAvoy ${ }^{45}$ ).

\section{Support for the gradient hypothesis}

Support for the FGF gradient hypothesis comes from a range of studies (reviewed in Chamberlain and McAvoy ${ }^{45}$ ). These include studies of the distribution of FGF and FGF activity in the ocular media, the expression of FGF receptors, and the effects of disturbing normal patterns of FGF expression and FGF signalling by genetic manipulation. 


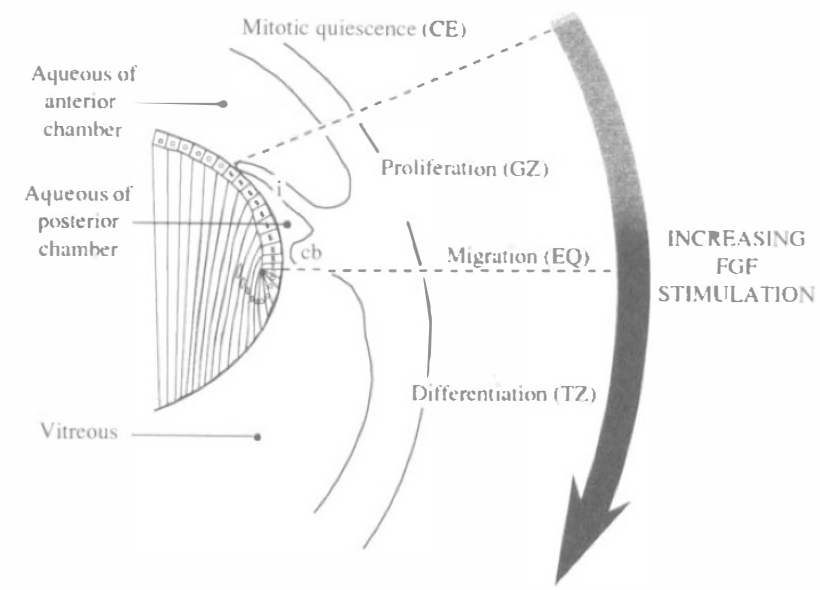

Fig. 9. Diagram of the eye indicating how anteroposterior patterns of lens cell behaviour may be determined by a gradient of FGF stimulation. In the mature lens, the epithelium can be divided into two main zones: the central epithelium (CE) and the germinative zone (GZ), which extends to the equator (EQ). Immediately posterior to the equator is the transitional zone (TZ). These zones coincide with compartments defined by the anatomy of the eye: the central epithelium is exposed to aqueous of the anterior chamber, the germinative zone is exposed to aqueous of the posterior chamber which is demarcated by the ciliary body $(c b)$ and iris (i). The transitional zone extends into the compartment that contains the vitreous. The cellular behaviours indicated are observed both in vivo and in lens epithelial explants cultured with increasing concentrations of FGF. Adapted from Chamberlain and McAvoy. ${ }^{45}$

\section{Differential distribution of FGF and FGF activity in the ocular media}

In vivo, patterns of lens cell organisation and activity correlate with the distribution of the ocular media. The anterior region of the lens is bathed by aqueous, while the region of the lens below the equator (where fibres differentiate) is bathed by vitreous (Fig. 9). We tested the hypothesis that the polarity of the lens is a reflection of differences in the way in which these ocular media influence the lens cells. Lens epithelial explants were cultured in either aqueous or vitreous. In explants exposed to vitreous the cells elongated, lost organelles, showed the appearance of plasma membrane interdigitations such as finger-like processes and balland-socket junctions, and nucleolar changes characteristic of early fibre denucleation ${ }^{51}$ (Fig. 10A). These explants became multilayered and also accumulated fibre-specific $\beta$-crystallin. In contrast, the cells in explants cultured with aqueous maintained an epithelial morphology (Fig. 10B) and accumulated little, or no, $\beta$-crystallin. ${ }^{51,52}$

Thus vitreous induced changes characteristic of fibre differentiation but aqueous did not. One obvious explanation for these different responses is that vitreous has a higher concentration of FGF than aqueous. For example, both FGF-1 and FGF-2 have been reported to be present in ocular media and biochemical analysis indicates that vitreous contains substantially more FGF than aqueous (reviewed in Chamberlain and McAvoy ${ }^{45}$ ). Fractionation of vitreous and testing fractions by both
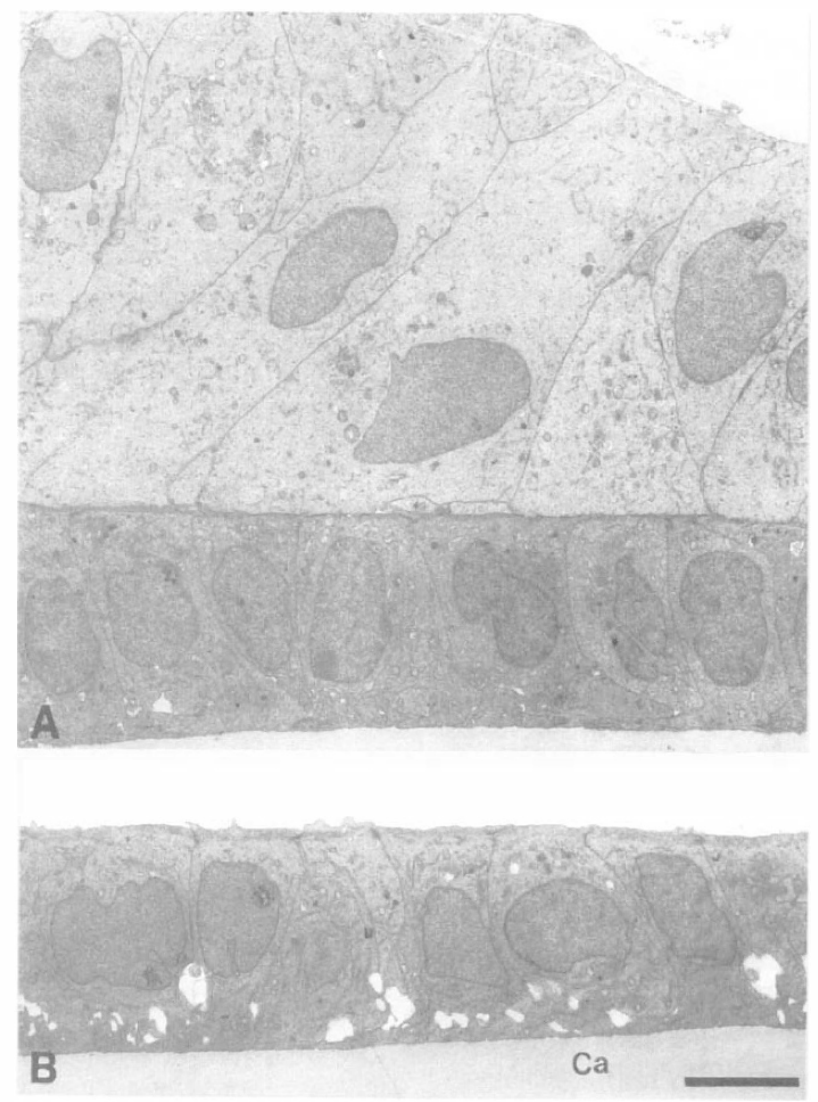

Fig. 10. Transmission electron micrographs of neonatal rat lens epithelial explants cultured with ocular media for 5 days. (A) In the presence of vitreous, explants thickened and many cells showed early fibre elongation characteristic of cells in the transitional zone (see Fig. 9). (B) In the presence of aqueous, cells remained in a monolayer on the lens capsule $(\mathrm{Ca})$ and retained a cuboidal epithelial morphology. Fresh bovine aqueous and vitreous were diluted with an equal volume of culture medium before use. Adapted from Lovicu et al..$^{51}$ Scale bar represents $5 \mu \mathrm{m}$.

FGF ELISA and biological assay confirmed that most of the fibre-differentiating activity of vitreous is FGFassociated. ${ }^{52}$

Thus a higher concentration of FGF in the vitreous than in the aqueous may help to ensure that fibre differentiation is restricted to the posterior compartment; however, as indicated above, the ability of the vitreous to promote fibre differentiation may not be due solely to its relatively high concentration of FGF. Other factors present in the vitreous may positively modulate the effects of FGF (reviewed in Chamberlain and McAvoy ${ }^{45}$ ). As one example, members of the insulin/IGF growth factor family may be involved as they can potentiate the fibre-differentiating effects of FGF in lens epithelial explants $^{53-55}$ and are present in the vitreous. ${ }^{56}$

\section{Distribution of FGF receptors}

Cellular responses to FGF are mediated via a family of four distinct, but highly homologous receptor genes (FGFR1-4; reviewed in Johnson and Williams ${ }^{57}$ ). Alternative splicing of these genes, particularly of immunoglobulin domain III, gives rise to numerous subtypes. Lens cells have been shown to express three of 
the FGFR genes: FGFR1, FGFR2 (splice versions IIIb and IIIc) and FGFR3 ${ }^{58-61}$ Detailed analyses of the expression patterns in the developing lens indicate that the three receptors are expressed in distinctly different spatiotemporal patterns during lens development. ${ }^{60,61}$ After the lens has formed, FGFR1 and FGFR2(IIIb) have very similar patterns in that they are weakly expressed in the anterior epithelium and become increasingly strongly expressed in the germinative and transitional zones

(Fig. 11). The FGFR3 gene also showed such an anteroposterior gradient of expression, except that peak expression of this receptor was found in the cortical fibres. In contrast, the FGFR2(IIIc) receptor was most strongly expressed in the epithelial cells and decreased as fibres differentiated. These results suggest that different combinations of FGFR may be involved in regulating different stages of FGF-induced fibre differentiation. The high expression levels of FGFR1, FGFR2(IIIb) and FGFR3 below the lens equator suggest that these cells are highly responsive to FGF. In addition, experiments on lens explants showed that FGF induces upregulation of FGFR1 mRNA, indicating that as cells become exposed to FGF they upregulate receptors and become more sensitive to FGF stimulation. ${ }^{60}$
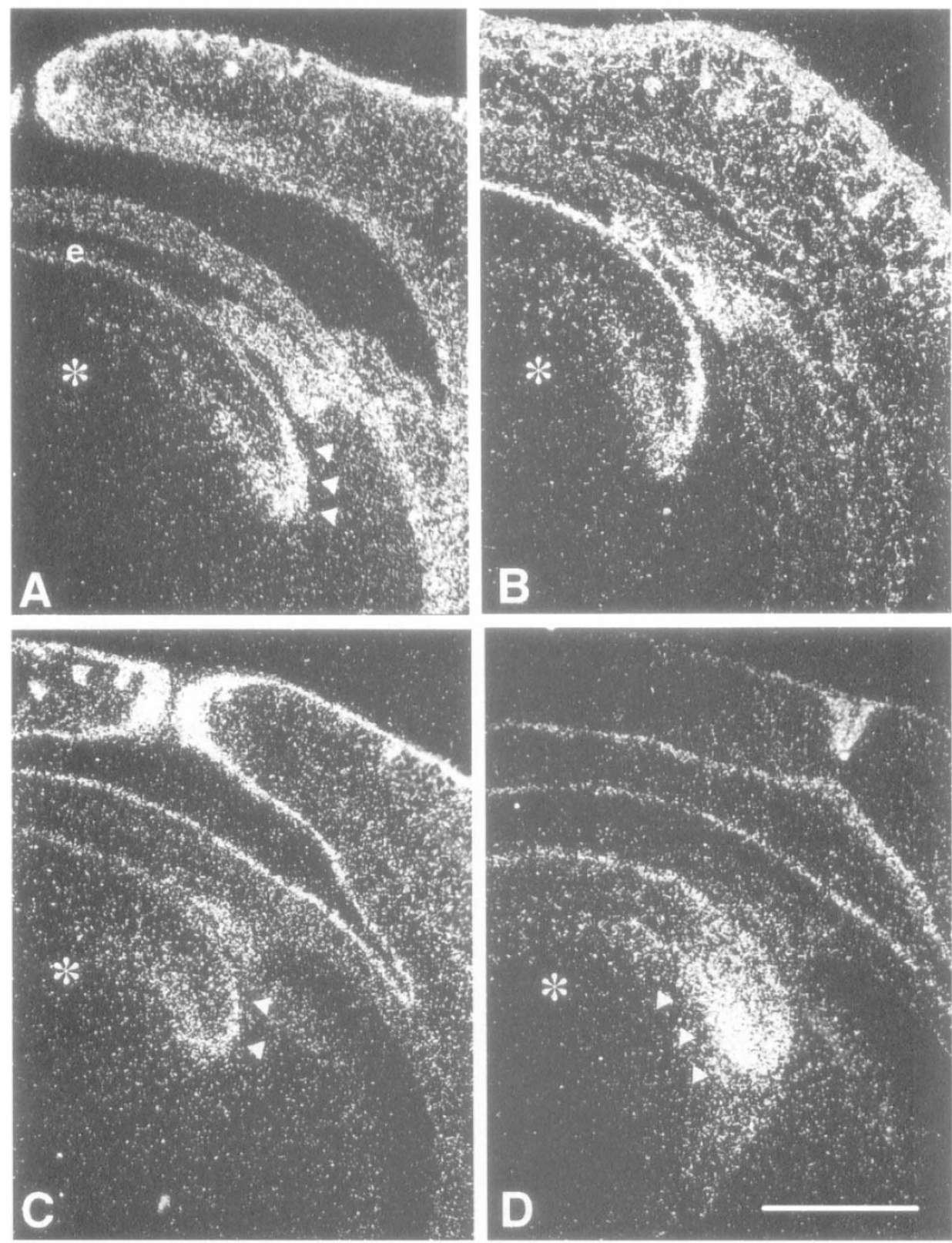

Fig. 11. Expression of FGFRs in the embryonic rat lens at E20. Dark- field micrographs show expression of mRNA for FGFR1 (A), FGFR2(IIIC) (B), FGRF2(IIIb) (C), FGFR3 (D). (A) There was weak signal for FGFR1 in the central epithelium (e), which increased towards the lens equator in the germinative zone. The strongest signals were in the transitional zone of the lens (arrowheads). See Fig. 9 for definition of lens regions. (B) FGFR1(IIIc) showed a uniform distribution throughout the epithelium and transitional zone. (C) FGFR2(IIIb) showed weak signal in the epithelium and stronger signal in the transitional zone (arrowheads). For FGFR1 and FGFR2 the signal decreased progressively in the inner and outer cortical fibres. (D) Signal for FGFR3 was detected in the central epithelium and increased in the germinative and transitional zone. Strongest signals were detected in the cortical fibres (arrowheads). No significant signal above background was detected for any of the receptors in the mature fibres (asterisk). Adapted from de Iongh et al. ${ }^{60,61}$ Scale bar represents $50 \mu \mathrm{m}$. 
Studies with transgenic mice provide strong support for the hypothesis that FGF influences the behaviour of lens cells in vivo. Using the $\alpha \mathrm{A}$-crystallin promoter, transgenic mice were generated that express high levels of various FGFs specifically in the lens. In these transgenic mice FGF-1, FGF-3, FGF-4, FGF-5, FGF-7, FGF-8 or FGF-9 induced the anterior epithelial cells to undergo premature fibre differentiation (Fig. 12). They lost their typical cuboidal epithelial morphology, became elongated and accumulated $\beta$-crystallin, which is normally restricted to the fibre mass. In most cases the lens lost its characteristic cellular polarity. ${ }^{62-65}$ Using this transgenic model, FGF-2 is the only member of the FGF family tested so far that did not induce differentiation in the epithelium. ${ }^{66}$

Further evidence for FGF involvement in fibre differentiation comes from studies on transgenic mice expressing a mutant form of FGFR1. ${ }^{67,68}$ Using the $\alpha \mathrm{A}$-crystallin promoter to express high levels of this mutant FGF receptor in the lens has a dominant-negative effect and inhibits FGF function. These transgenic mice displayed defective fibre differentiation. The most severe phenotype was a small abnormal lens consisting of a large central vacuole surrounded on the anterior side by a layer of epithelial cells and on the lateral and posterior sides by short, swollen, nucleated fibre cells. ${ }^{68}$

Results from these transgenic studies lend strong support to the hypothesis that in the normal situation members of the FGF family are involved in regulating fibre differentiation and determining lens polarity. Thus, it is proposed that lens epithelial cells in the anterior segment normally receive insufficient FGF stimulation to

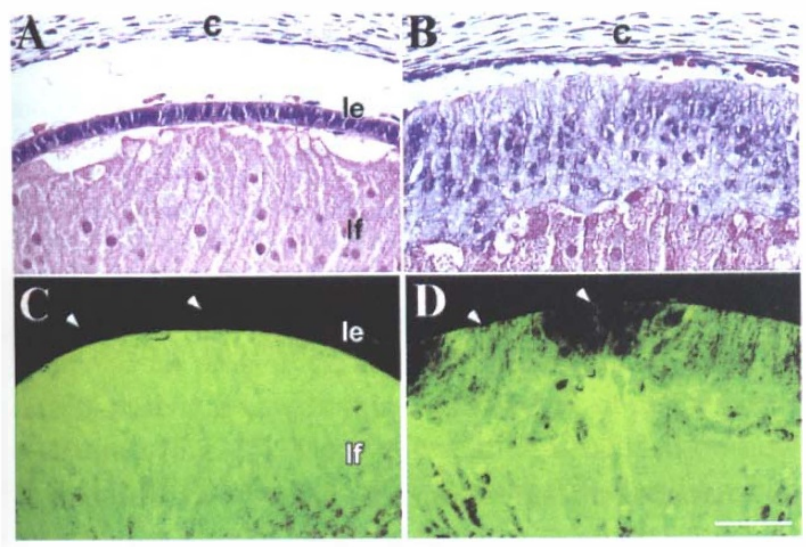

Fig. 12. Induction of fibre differentiation by FGF-4 in transgenic mice. Sections of embryonic day 15.5 non-transgenic $(A, C)$ and transgenic $(B, D)$ eyes either stained with haematoxylin and eosin $(A, B)$ or immunolabelled for $\beta$-crystallin expression $(C, D)$. In transgenic mice, anterior lens epithelial cells undergo extensive elongation (B), differentiating into fibres as shown by the expression of $\beta$-crystallin (D). Small regions of epithelial cells did not express $\beta$-crystallin, unlike their more differentiated neighbouring cells, ( $D$, arrowheads). In nontransgenic mice, the lens maintains its distinct polarity with a monolayer of cuboidal epithelial cells $(A, l e)$ overlying a full complement of fibre cells ( $l f)$ reactive for $\beta$-crystallin. In these mice, $\beta$-crystallin is not expressed in the anterior lens epithelium ( $c$, le, arrowheads). Adapted from Lovicu and Overbeek. ${ }^{64}$ Scale bar represents $60 \mu \mathrm{m}$. induce fibre differentiation; however, when they shift below the equator and enter the vitreous compartment they receive a higher level of FGF stimulation and fibre differentiation is the result (Fig. 13). The transgenic studies show that most of the FGFs tested exhibit a capacity to induce fibre differentiation. This is consistent with the observation that lens cells express three of the four FGF receptor genes, thereby conferring on lens cells the capacity to bind a wide range of FGF family members. However, it is not clear yet which of the currently known 18 FGFs are involved in this process in the normal lens.

\section{Pathological development}

Growth factors are also commonly involved in pathological development. Work in our laboratory has shown that members of the transforming growth factorbeta (TGF $\beta$ ) family have a disruptive influence on lens cellular architecture and can induce changes that are characteristic of some forms of human cataract. Using our rat lens epithelial explant culture system and cultured whole lenses, we have shown that TGF $\beta$ induces lens epithelial cells to undergo a pathway of differentiation that is distinctly different from that induced by FGF. TFG $\beta$ induces the formation of distinct opacities in the lens that correspond to plaques of spindle-shaped cells which contain $\alpha$-smooth muscle actin and desmin, and accumulations of extracellular matrix that contain collagen types I and III, fibronectin and tenascin. Apoptotic cell death and localised capsule wrinkling are also features of TGF $\beta$-induced changes ${ }^{69-71}$ (Fig. 14). Some or all of these changes are typically found in subcapsular cataracts and in after cataract (also known as posterior capsular opacification) that often arises from epithelial cells left behind after cataract surgery. In general, these features are atypical of epithelial cells but

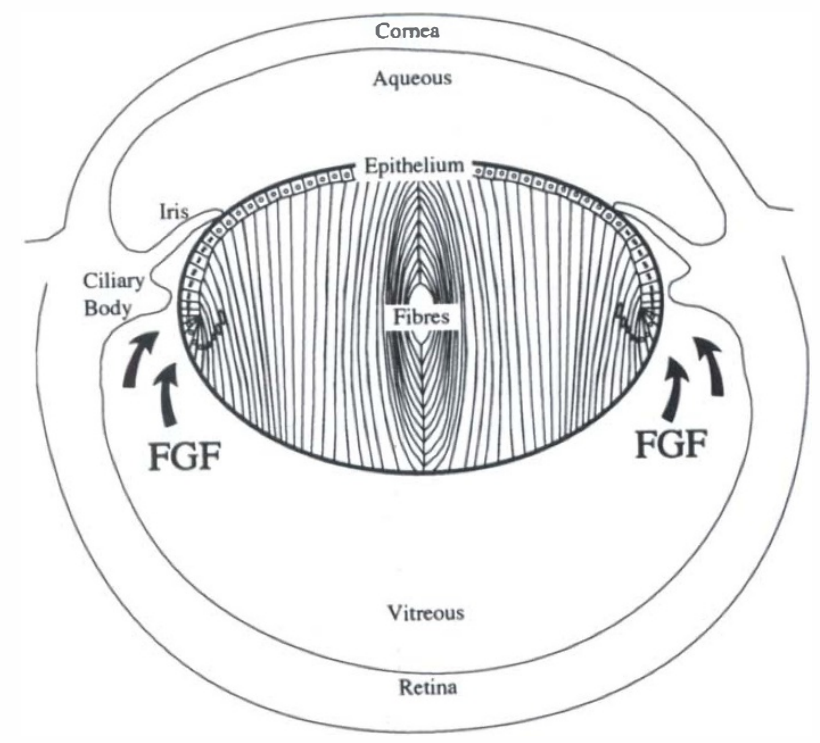

Fig. 13. Diagram of the eye illustrating the proposed role of FGF in determining lens polarity. Lens cells receive a strong enough stimulus to promote fibre differentiation only when they enter the vitreous compartment. Adapted from Chamberlain and McAvoy. ${ }^{45}$ 

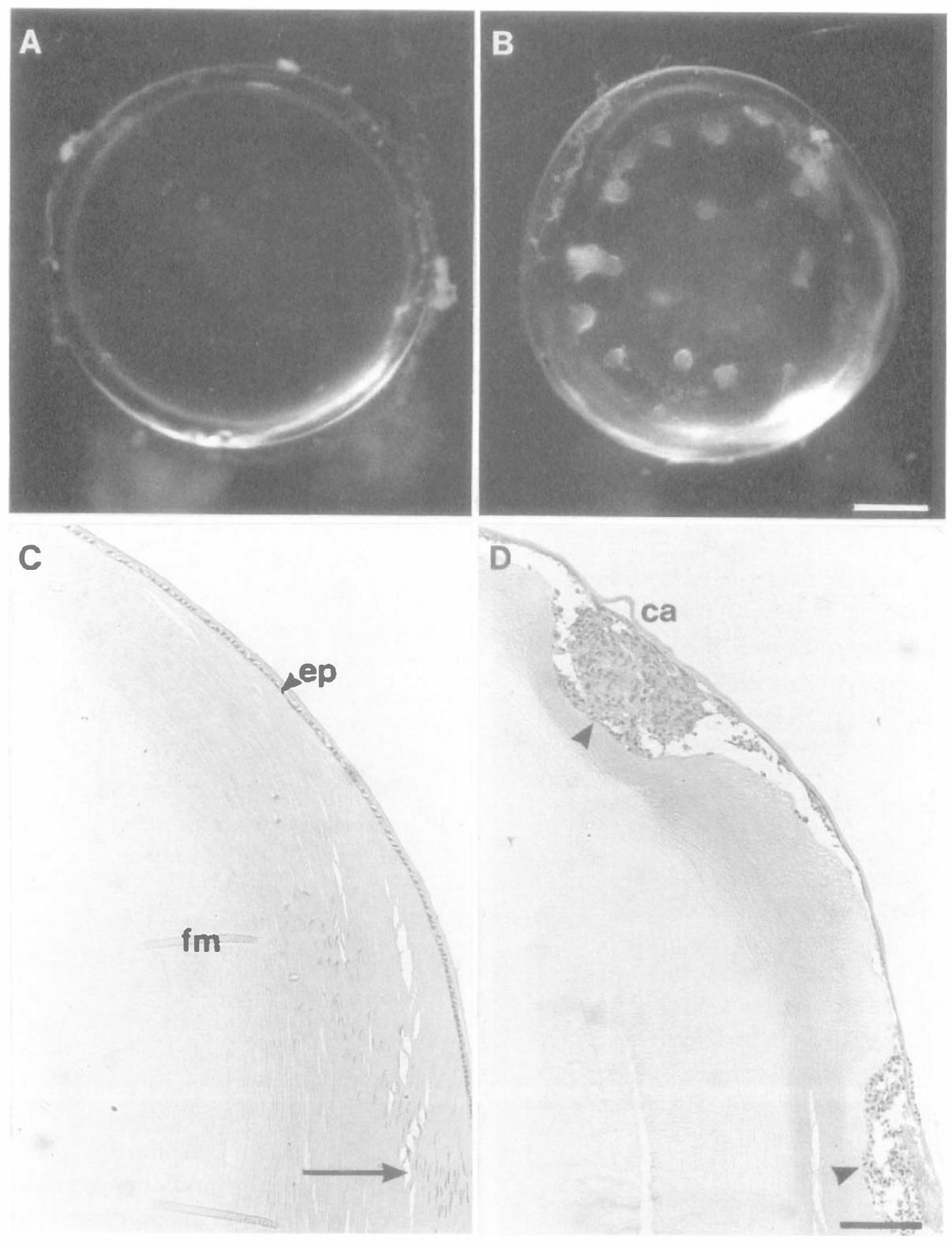

Fig. 14. The effect of TGF $\beta$ on lens transparency and morphology. Lenses from 21-day-old rats were cultured for 5 days in medium 199 ( $A, C$; controls) or with $5 \mathrm{ng} / \mathrm{ml} T G F \beta 2(B, D)$. Lenses were photographed through the posterior pole $(A, B)$ or embedded, sectioned sagittally and stained with haemotoxylin-eosin $(C, D)$. In $(C)$ and $(D)$, the equator of the lens is at the bottom edge of the micrograph (arrow in $C$; arrowhead in $D$ ). Lenses cultured with TGF $\beta$ developed distinct anterior opacities (B). These appeared to correspond with plaques (arrowheads) that lay immediately beneath the lens capsule (ca) and disrupted the normal architecture of the lens (D). These changes were not observed in control lenses cultured without $T G F \beta$, which maintained a normal monolayer of epithelial cells (ep) covering the fibre mass ( $f m$ ). Adapted from Chamberlain and McAvoy. ${ }^{45}$ Scale bars represent: $(A, B), 400 \mu m ;(C, D), 250 \mu m$.

are typical of myofibroblastic/fibroblastic cells. This indicates that TGF $\beta$-induced cataract is characterised by lens epithelial cells differentiating along a mesenchymal pathway, in other words, undergoing an 'epithelial-mesenchymal transition' ${ }^{72}$

TGF $\beta$ is present in and near the lens and lens cells express TGF $\beta$ receptors. ${ }^{73,74}$ Therefore, in the normal eye its bioavailability must be tightly regulated. Investigating this regulation has been a major focus of our recent research. Besides the widely known fact that TGF $\beta$ is generally produced in a latent form, we have shown that there are important additional levels at which it might be regulated in the eye. For example, the ocular media contain molecule(s) that inhibit TGF $\beta$ activity and block its cataractogenic effects on lens cells. ${ }^{75}$ Vitreous was particularly effective in this respect. The serum protein $\alpha 2$-macroglobulin, a known TGF $\beta$ inhibitor in some other systems, was also shown to protect the lens against TGF $\beta$-induced changes and substantial amounts of this protein were found in vitreous. The sensitivity of lens cells to TGF $\beta$ may also be modulated by various factors. For example, experiments with ovariectomised rats have shown that oestrogen protects lens cells from the cataractogenic effects of TGF $\beta .^{71}$ These studies with rats are consistent with epidemiological studies that also suggest female hormones have a role in protecting against cataract. 

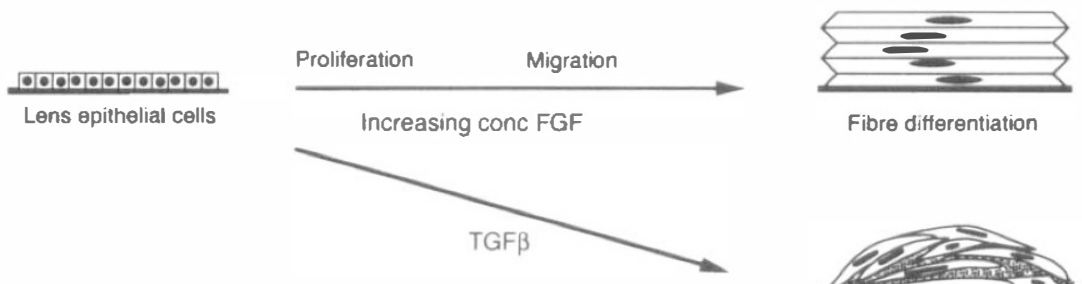

Fibre differentiation

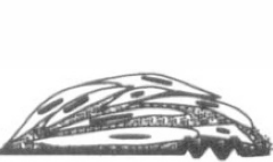

Pathological phenotype

Fig. 15. Diagram illustrating the key roles played by FGF and TGF $\beta$ in modulating the lens cell phenotype. FGF induces processes that are features of normal lens growth and differentiation, whereas TGF $\beta$ induces pathological changes.

Thus, the ability of TGF $\beta$ to induce lens epithelial cells along the pathological pathway of differentiation may be influenced by various factors. These will be important to identify as they may play a role in making lens cells more, or less, susceptible to undergoing cataractous changes. It will also be important to characterise fully the phenotypic changes induced by TGF $\beta$. Currently it is not clear if the myofibroblastic/fibroblastic cells retain any normal lens epithelial markers or whether they lose all epithelial features and represent a distinct cell type with different patterns of cellular behaviour.

\section{Summary}

This brief review of lens development serves to remind us that there are many processes involved in the formation and maintenance of a normal lens. It is only relatively recently that researchers have begun to investigate the molecular basis of lens development so there is much to be done. Important areas for research include: determining the hierarchy of transcription factors involved in lens induction and differentiation, and identifying the mechanisms whereby they influence complex patterns of gene expression. Growth factors are clearly important regulators of lens cell behaviour and there is now strong evidence that FGF has a key role in inducing fibre differentiation and maintaining normal cellular architecture (Fig. 15). In contrast, TGF $\beta$ induces an abnormal phenotype and disrupts normal cellular architecture in a way that is characteristic of major forms of cataract (Fig. 15). More information is needed on how FGF and TGF $\beta$ bioavailability are regulated and how their effects are mediated so that we can understand better how they influence the progress of lens cells along normal or pathological pathways of growth and differentiation. This will also be important for the identification of factors, or conditions, that favour transition from one pathway to the other. Finally, understanding the interplay between growth factors and transcription factors in normal and pathological lens development is a challenging and important area for future study.

Thanks go to Richard Stump and Roland Smith for their assistance with preparing the figures for this manuscript.

\section{References}

1. Spemann H. Über correlation in der Enwickelung des Auges. Verh Anat Ges 1901;15:61-79.

2. McAvoy JW. Developmental biology of the lens. In: Duncan $\mathrm{G}$, editor. Mechanisms of cataract formation in the human lens. London: Academic Press, 1981:7-46.

3. Jacobson AG. Inductive processes in embryonic development. Science 1966;152:25-34.

4. Grainger RM, Mannion JE, Cook TL Jr, Zygar CA. Defining intermediate stages in cell determination: acquisition of a lens-forming bias in head ectoderm during lens determination. Dev Genet 1997;20:246-57.

5. Saha MS, Servetnick M, Grainger RM. Vertebrate eye development. Curr Biol 1992;2:582-8.

6. Halder G, Callaerts P, Gehring WJ. Induction of ectopic eyes by targeted expression of the eyeless gene in Drosophila. Science 1995;267:1788-92.

7. Altmann CR, Chow RL, Lang RA, Hemmati-Brivanlou A. Lens induction by Pax-6 in Xenopus laevis. Dev Biol 1997;185:119-23.

8. Grindley JG, Davidson DR, Hill RE. The role of Pax-6 in eye and nasal development. Development 1995;121:1433-42.

9. Stadler HS, Solursh M. Characterisation of the homeoboxcontaining gene GH6 identifies novel regions of homeobox gene expression in the developing chick embryo. Dev Biol 1994;161:251-62.

10. Bonini NM, Bui QT, Gray-Board GL, Warrick JM. The Drosophila eyes absent gene directs ectopic eye formation in a pathway conserved between flies and vertebrates. Development 1997;124:4819-26.

11. Yoshida K, Imaki J, Koyama Y, Harada T, Shinmei Y, Oishi C, et al. Differential expression of maf- 1 and maf-2 genes in the developing rat lens. Invest Ophthalmol Vis Sci 1997;38:2679-83.

12. Ogino $\mathrm{H}$, Yasuda K. Induction of lens differentiation by activation of a bZIP transcription factor, L-Maf. Science 1998;280:115-8.

13. Liu Q, Ji X, Breitman ML, Hitchcock PF, Swaroop A. Expression of the bZIP transcription factor gene $\mathrm{Nrl}$ in the developing nervous system. Oncogene 1996;12:207-11.

14. Monaghan AP, Davidson DR, Sime C, Graham E, Baldock R, Bhattacharya SS, et al. The Msh-like homeobox genes define domains in the developing vertebrae eye. Development 1991;112:1053-61.

15. Foerst-Potts L, Sadler TW. Disruption of Msx-1 and Msx-2 reveals roles for these genes in craniofacial, eye, and axial development. Dev Dynam 1997;209:70-84.

16. Oliver G, Sosa-Pineda B, Geisendorf S, Spana EP, Doe CQ, Gruss P. Prox 1, a prospero-related homeobox gene expressed during mouse development. Mech Dev 1993;44:3-16.

17. Tomarev SI, Sundin O, Banerjee-Basu S, Duncan MK, Yang JM, Piatigorsky J. Chicken homeobox gene Prox 1 related to Drosophila prospero is expressed in the developing lens and retina. Dev Dynam 1996;206:354-67. 
18. Semina EV, Reiter RS, Murray JC. Isolation of a new homeobox gene belonging to the Pitx/Rieg family: expression during lens development and mapping to the aphakia region on mouse chromosome 19. Hum Mol Genet 1997;6:2109-16.

19. Oliver G, Mailhos A, Wehr R, Copeland NG, Jenkins NA, Gruss P. Six3, a murine homologue of the sine oculis gene, demarcates the most anterior border of the developing neural plate and is expressed during eye development. Development 1995;121:4045-55.

20. Oliver G, Loosli F, Koster R, Wittbrodt J, Gruss P. Ectopic lens induction in fish in response to the murine homeobox gene Six3. Mech Dev 1996;60:233-9.

21. Kamachi Y, Sockanathan S, Liu Q, Breitman M, Lovell-Badge $\mathrm{R}$, Kondoh $\mathrm{H}$. Involvement of SOX proteins in lens-specific activation of crystallin genes. EMBO J 1995;14:3510-9.

22. Nishiguchi S, Wood H, Kondoh H, Lovell-Badge R, Episkopou V. Sox1 directly regulates the gamma-crystallin genes and is essential for lens development in mice. Genes Dev 1998;12:776-81.

23. Pignoni F, Hu B, Zavitz KH, Xiao J, Garrity PA, Zipursky S. The eye-specification proteins So and Eya form a complex and regulate multiple steps in Drosophila eye development. Cell 1997;91:881-91.

24. McAvoy JW. Cytoplasmic processes interconnect lens placode and optic vesicle during eye morphogenesis. Exp Eye Res 1980;31:527-34.

25. Silver J, Hughes JFW. The role of cell death during morphogenesis of the mammalian eye. J Morphol 1973;140:159-70.

26. Harding CV, Reddan JR, Unakar NJ, Bagchi M. The control of cell division in the ocular lens. Int Rev Cytol 1971;31:215-300.

27. McAvoy JW. Cell division, cell elongation and distribution of $\alpha-, \beta$ - and $\gamma$-crystallins in the rat lens. J Embryol Exp Morphol 1978;44:149-65.

28. McAvoy JW. Cell division, cell elongation and the coordination of crystallin gene expression during lens morphogenesis in the rat. J Embryol Exp Morphol 1978;45:271-81.

29. Van Leen RW, Breuer ML, Lubsen NH, Schoenmakers JGG. Developmental expression of crystallin genes: in situ hybridisation reveals a differential localisation of specific mRNAs. Dev Biol 1987;123:338-45.

30. Coulombre JL, Coulombre AJ. Lens development: fibre elongation and lens orientation. Science 1963;142:1489-90.

31. Yamamoto Y. Growth of lens and ocular environment: role of neural retina in the growth of mouse lens as revealed by implantation experiment. Dev Growth Differ 1976;18:273-8.

32. Chamberlain CG, McAvoy JW. Evidence that fibroblast growth factor promotes lens fibre differentiation. Curr Eye Res 1987;6:1165-9.

33. Chamberlain CG, McAvoy JW. Induction of lens fibre differentiation by acidic and basic fibroblast growth factor (FGF). Growth Factors 1989;1:125-34.

34. McAvoy JW, Chamberlain CG. Fibroblast growth factor (FGF) induces different responses in lens epithelial cells depending on its concentration. Development 1989;107:221-8.

35. Lovicu FJ, McAvoy JW. Structural analysis of lens epithelial explants induced to differentiate into fibres by fibroblast growth factor (FGF). Exp Eye Res 1989;49:479-94.

36. Lovicu FJ, McAvoy JW. The age of rats affects response of lens epithelial explants to fibroblast growth factor: an ultrastructural analysis. Invest Ophthalmol Vis Sci 1992;33:2269-78.

37. Lovicu FJ, McAvoy JW. A structural analysis of fibroblast growth factor (FGF)-induced lens fibre differentiation in vitro. J Comput Assist Micros 1993;5:57-63.

38. Kuwabara T, Imaizumi M. Denucleation process of the lens. Invest Ophthalmol 1974;13:973-81.
39. Kuwabara T. The maturation of the lens cell: a morphologic study. Exp Eye Res 1975;20:427-43.

40. Harding CV, Susan SR, Murphy H. Scanning electron microscopy of the adult rabbit lens. Ophthalmic Res 1976;8:443-55.

41. Richardson NA, McAvoy JW. Age-related changes in fibre differentiation of rat lens epithelial explants exposed to fibroblast growth factor. Exp Eye Res 1990;50:203-11.

42. Richardson NA, McAvoy JW, Chamberlain CG. Age of rats affects response of lens epithelial explants to fibroblast growth factor. Exp Eye Res 1992;55:649-56.

43. Peek R, McAvoy JW, Lubsen NH, Schoenmakers JGG. Rise and fall of crystallin gene messenger levels during fibroblast growth factor induced terminal differentiation of lens cells. Dev Biol 1992;152:152-60.

44. Ohbayashi N, Hoshikawa M, Kimura S, Yamasaki M, Fukui $\mathrm{S}$, Itoh N. Structure and expression of the mRNA encoding a novel fibroblast growth factor, FGF-18. J Biol Chem 1998;29:18161-4.

45. Chamberlain CG, McAvoy JW. Fibre differentiation and polarity in the mammalian lens: a key role for FGF. Prog Ret Eye Res 1997;16:443-78.

46. Lovicu FJ, de Iongh RU, McAvoy JW. Expression of FGF-1 and FGF-2 mRNA during lens morphogenesis, differentiation and growth. Curr Eye Res 1997;16:222-30.

47. Hartung H, Feldman B, Lovec H, Coulier F, Birnbaum D, Goldfarb M. Murine FGF-12 and FGF-13: expression in embryonic nervous system, connective tissue and heart. Mech Dev 1997;64:31-9.

48. Wilkinson DG, Bhatt S, McMahon AP. Expression patterns of the FGF-related proto-oncogene int-2 suggests multiple roles in fetal development. Development 1989;105:131-6.

49. Kitaoka T, Aotaki-Keen AE, Hjelmeland LM. Distribution of FGF-5 in the rhesus macaque retina. Invest Ophthalmol Vis Sci 1994;35:3189-98.

50. McAvoy JW, Chamberlain CG, de Iongh RU, Richardson NA, Lovicu FJ. The role of fibroblast growth factor in eye lens development. Ann NY Acad Sci 1991;638:256-74.

51. Lovicu FJ, Chamberlain CG, McAvoy JW. Differential effects of aqueous and vitreous on fibre differentiation and extracellular matrix accumulation in lens epithelial explants. Invest Ophthalmol Vis Sci 1995;36:1459-69.

52. Schulz MW, Chamberlain CG, de Iongh RU, McAvoy JW. Acidic and basic FGF in ocular media and lens: implications for lens polarity and growth patterns. Development 1993;118:117-26.

53. Chamberlain CG, McAvoy JW, Richardson NA. The effects of insulin and basic fibroblast growth factor on fibre differentiation in rat lens epithelial explants. Growth Factors 1991;4:183-8.

54. Richardson NA, Chamberlain CG, McAvoy JW. IGF-1 enhancement of FGF-induced lens fibre differentiation in rats of different ages. Invest Ophthalmol Vis Sci 1993;34:3303-12.

55. Liu J, Chamberlain CG, McAvoy JW. IGF enhancement of FGF-induced fibre differentiation and DNA synthesis in lens explants. Exp Eye Res 1996;63:621-9.

56. Arnold DR, Moshayedi P, Schoen TR, Jones BE, Chader GJ, Waldbillig RJ. Distribution of IGF-I and -II, IGF binding proteins (IGFBPs) and IGFBP mRNA in ocular fluids and tissues: potential sites of synthesis of IGFBPs in aqueous and vitreous. Exp Eye Res 1993;56:555-65.

57. Johnson DE, Williams LT. Structural and functional diversity in the FGF receptor multigene family. Adv Cancer Res 1993;60:1-41.

58. Orr-Urtreger A, Bedford MT, Burakova T, Arman E, Zimmer $\mathrm{Y}$, Yayon A, et al. Developmental localisation of the splicing alternatives of fibroblast growth factor receptor-2 (FGFR2). Dev Biol 1993;158:475-86.

59. Peters K, Ornitz D, Werner S, Williams L. Unique expression pattern of the FGF receptor-3 gene during mouse organogenesis. Dev Biol 1993;155:423-30. 
60. de Iongh RU, Lovicu FJ, Hanneken A, Baird A, McAvoy JW FGF receptor-1 (flg) expression is correlated with fibre differentiation during rat lens morphogenesis. Dev Dynam 1996;206:412-26.

61. de Iongh RU, Lovicu FJ, Chamberlain CG, McAvoy JW. Differential expression of fibroblast growth factor receptors during rat lens morphogenesis and growth. Invest Ophthalmol Vis Sci 1997;38:1688-99.

62. Robinson ML, Overbeek PA, Verran DJ, Grizzle WE, Stockard CR, Friesel R, et al. Extracellular FGF-1 acts as a lens differentiation factor in transgenic mice. Development 1995;121:505-14.

63. Robinson ML, Ohtaka-Maruyama C, Chan C, Jamieson S, Dickson C, Overbeek PA, et al. Disregulation of ocular morphogenesis by lens-specific expression of FGF-3/int-2 in transgenic mice. Dev Biol 1998;198:13-31.

64. Lovicu FJ, Overbeek PA. Overlapping effects of different members of the FGF family on lens fibre differentiation in transgenic mice. Development 1998;125:3365-77.

65. Srinivasan Y, Overbeek PA. Expression of lens specific fibroblast growth factor (FGF5) causes altered epithelial cell morphology and degeneration of fibre cells. Invest Ophthalmol Vis Sci (ARVO Suppl) 1996;37:S924.

66. Stolen CG, Jackson MK, Griep AE. Overexpression of FGF-2 modulates fibre cell differentiation and survival in the mouse lens. Development 1997;124:4009-17.

67. Chow RL, Diez Roux G, Roghani M, Palmer MA, Rifkin D, Moscatelli D, et al. FGF suppresses apoptosis and induces differentiation of fibre cells in the mouse lens. Development 1995;121:4383-93.

68. Robinson ML, MacMillan-Crow LA, Thompson JA, Overbeek PA. Expression of a truncated FGF receptor results in defective lens development in transgenic mice. Development 1995;121:3959-67.
69. Liu J, Hales AM, Chamberlain CG, McAvoy JW. Induction of cataract-like changes in rat lens epithelial explants by transforming growth factor $\beta$. Invest Ophthalmol Vis Sci 1994;35:388-401.

70. Hales AM, Chamberlain CG, McAvoy JW. Cataract induction in lenses cultured with transforming growth factor- $\beta$. Invest Ophthalmol Vis Sci 1995;36:1709-13.

71. Hales AM, Chamberlain CG, Murphy CR, McAvoy JW. Estrogen protects lenses against cataract induced by transforming growth factor $\beta$ (TGF $\beta$ ). J Exp Med 1997;185:273-80.

72. McAvoy JW, Schulz MW, Maruno KA, Chamberlain CG, Lovicu FJ. TGF- $\beta$-induced cataract is characterised by epithelial-mesenchymal transition and apoptosis. Invest Ophthalmol Vis Sci (ARVO Suppl) 1998;39:S7.

73. de Iongh RU, Gordon-Thomson C, Chamberlain CG, McAvoy JW. Age-related competence of TGF $\beta$ response in rat lens epithelium correlates with receptor expression. Invest Ophthalmol Vis Sci (ARVO Suppl) 1996;37:S983.

74. Gordon-Thomson C, de Iongh RU, Hales AM, Chamberlain CG, McAvoy JW. Differential cataractogenic potency of TGF- $\beta 1, T G F \beta-2$ and TGF $\beta-3$ and their expression in the postnatal rat eye. Invest Ophthalmol Vis Sci 1998;39:1399-409.

75. Schulz MW, Chamberlain CG, McAvoy JW. Inhibition of TGFß-induced cataractous changes in lens explants by ocular media and $\alpha 2$-macroglobulin. Invest Ophthalmol Vis Sci 1996;37:1509-19.

76. de Iongh RU, McAvoy JW. Spatio-temporal distribution of acidic and basic FGF indicates a role for FGF in rat lens morphogenesis. Dev Dynam 1993;198:190-202.

77. McAvoy JW. The spatial relationship between presumptive lens and optic vesicle/cup during early eye morphogenesis in the rat. Exp Eye Res 1981;33:447-58. 